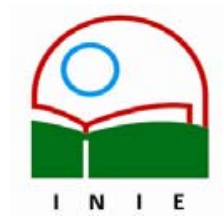

Universidad de Costa Rica

Facultad de Educación

Instituto de Investigación en Educación

ACTUALIDADES INVESTIGATIVAS EN EDUCACION

\title{
LA EXPRESIÓN DE LA POESÍA A TRAVÉS DE LAS ARTES PLÁSTICAS, UNA EXPERIENCIA PEDAGÓGICA DE INTEGRACIÓN CURRICULAR
}

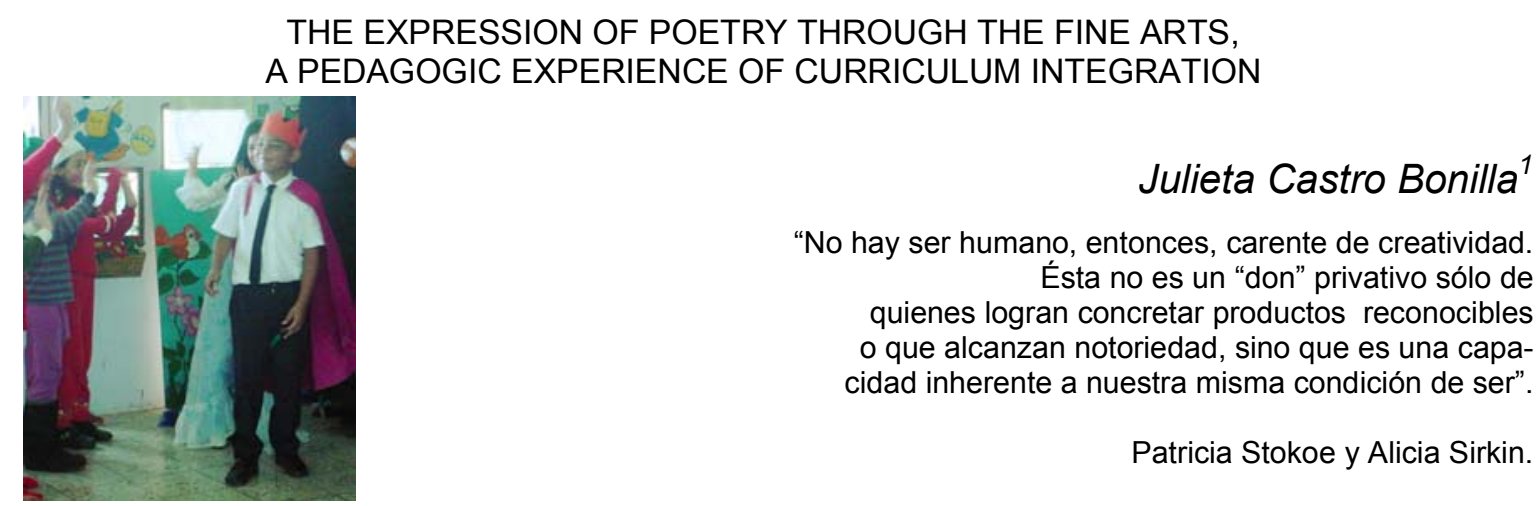

Resumen: El presente artículo se refiere a una experiencia pedagógica llevada a la práctica en la Escuela de Platanares en el Cantón de Moravia, San José. De ésta se rescatan dos aspectos, en primer lugar, un innovador trabajo de integración curricular entre la expresión plástica y la poesía; en segundo lugar se resalta la importancia de un trabajo conjunto entre padres y madres de familia, docentes y una población estudiantil que conforma dos secciones de Tercer Grado de la Educación General Básica. Se hace énfasis en un trabajo de cooperación y colaboración de parte de las poblaciones participantes, incluyendo la apertura mostrada por la dirección de la Escuela, lo que hizo posible el logro de los objetivos propuestos.

La autora del presente artículo, quien además fue la responsable de coordinar la actividad, considera que el trabajo realizado en la institución logró un final exitoso gracias a la contribución sistemática de las partes involucradas, ya que la misma permitió la participación de todos y todas en igualdad de condiciones, sin distingo de edad, condición social y formación académica.

Se considera importante mencionar que en la actividad, también participaron en calidad de asesoras, un grupo de profesionales de la educación con experiencia y formación en diferentes especialidades, entre las que se mencionan: música, artes plásticas, poesía, planificación curricular, evaluación educativa, situación que favoreció en los participantes el desarrollo de una personalidad integral.

Se espera que las experiencias vividas por las maestras puedan ser transferidas y desarrolladas en otros contextos y niveles académicos, ya que la misma representó un verdadero reto y éxito para las poblaciones involucradas.

Palabras clave: integración curricular, expresión plástica, poesía, docentes, estudiantes, padres y madres de familia.

Abstract: The present article refers to a pedagogic experience carried out in the Primary School of Platanares; an experience that dealt with curricular integration between the fine arts and poetry. In addition, the relevance of team work by parents, teachers and the students of two Primary School third-grade sections is highlighted.

We make emphasis on the cooperative labor and partnership from the aforementioned populations, as well as the attitude of openness shown by the school's Principal Office, as the causes behind the successful attainment of the proposed objectives.

The article's author, who as also the activity's coordinator, considers that the work finished in the institution had a successful result due to the organized cooperation of all the involved parties. This situation allowed everybody to participate in equal conditions; without age, social condition or academic training becoming reasons for discrimination.

It's important to mention that a group of experienced and trained professionals in fields such as music, the fine arts, poetry, curricular planning and educative evaluation took part in the activity as consultants. This situation favored the development of an integral personality in the benefited parties.

It is expected that the teacher's experiences will be communicated and transfered to other academic contexts and levels, since this activity was a true challenge and success for the involved parties.

Keywords: curricular integration / expression through the fine arts / poetry / Teachers students and parents.

\footnotetext{
1 Magíster en Ciencias de la Educación con énfasis en Educación Artística.

Licenciada en Bellas Artes con especialidad en Pintura. Profesora de Educación Secundaria con énfasis en Artes Plásticas. Actualmente es profesora de la Escuela de Formación Docente e Investigadora del Instituto de Investigación en Educación (INIE) de la Universidad de Costa Rica.
}

Correo electrónico: inie@cariari.ucr.ac.cr

Artículo recibido: 6 de marzo, 2006

Aprobado: 27 de abril, 2006 


\section{Introducción}

En el presente artículo se brinda una visión general respecto de la experiencia pedagógica que se llevó a la práctica en el año 2004 en la Escuela de Platanares, ubicada en el Cantón de Moravia, actividad que se realizó gracias a la colaboración del Instituto de Investigación en Educación (INIE). En ésta se exploraron algunos elementos que sirvieron de base para comprobar el nivel de conocimiento que los participantes poseían sobre la poesía y la expresión plástica, por lo que se elaboró un diagnóstico que permitió detectar los hábitos de lectura y el interés por esas áreas expresivas en la población participante. Los resultados permitieron la planificación de actividades de integración curricular que favorecieron el logro de los objetivos propuestos. Como parte de la experiencia también se realizó una evaluación cuyo propósito fue valorar las actividades y la participación de las partes involucradas, con el fin de aprovechar los resultados para repetirla en otros contextos educativos y con la aplicación de otras áreas del currículum escolar.

Al tener presente que el sistema educativo crece respecto al factor cuantitativo y en el sentido cualitativo, como docentes tenemos la responsabilidad de estudiar de manera sistemática la actualización de temas y contenidos curriculares, así como la aplicación de técnicas de enseñanza innovadoras.

Con el propósito de brindar ofertas de calidad a la población estudiantil, también se consideró relevante la participación de los padres y madres de familia, por lo que se les invitó a formar parte de las experiencias didácticas. Esta población decide involucrarse en las prácticas que se llevarían cabo, ya que, según ellos "las instituciones nunca nos toma en cuenta para la programación de este tipo de actividades, consideradas fundamentales para nuestro crecimiento personal...". Además, indican que, “...a cualquier edad se puede aprender". Por lo que acudieron rápidamente a la invitación que se les hacía.

La actividad pedagógica quedó conformada de la siguiente manera:

- Veintiocho niños y niñas que integran dos secciones del Tercer Grado de la Educación General Básica.

- Diecisiete padres y madres de familia.

- Dos maestras responsables de las secciones mencionadas.

- Un grupo de docentes que pertenecen la Sociedad Internacional de educadoras Delta, Kappa, Gamma², quienes, con su experiencia, dedicación y formación

\footnotetext{
${ }^{2}$ La Sociedad Internacional de Educadoras Delta, Kappa, Gamma, promueve la superación profesional y el crecimiento personal de las mujeres educadoras, así como la excelencia en el área educativa. 
académica, brindaron asesoría directa a las dos maestras, aunque en algunos de los talleres trabajaron con la población estudiantil y sus familiares.

Conviene destacar de la actividad dos aspectos fundamentales, un innovador trabajo de integración curricular entre la expresión plástica y la poesía; y el desarrollo de actividades conjuntas entre padres y madres de familia, docentes y una población estudiantil que con entusiasmo participa en las ofertas de aprendizaje que se organizaron.

La autora del artículo, quien además fue la responsable de coordinar la actividad, considera que un trabajo como el que se experimentó en esa institución logró un final exitoso, gracias a la colaboración y cooperación decidida de las poblaciones participantes, incluyendo la apertura mostrada por la dirección de la Escuela.

Las fotografías que aparecen en el documento, corresponden a las actividades de integración curricular, en la que la poesía, las artes plásticas y la expresión corporal se planifican desde una programación de experiencias lúdicas.

Sabemos que el currículum escolar le brinda mayor importancia al desarrollo del pensamiento lógico y a todas las acciones que giran en torno a éste; descuidando la mayoría de las veces las actividades artísticas, ya que además de ser relegadas a las "horas de recreación", o a la "copia o calco de dibujos", se abandona el desarrollo del pensamiento divergente, lateral o simplemente "creativo", situación que no favorece la creatividad infantil. El pensamiento creativo se desarrolla a través de la planificación de actividades artísticas, donde no hay respuesta única a un problema, como es el caso de la matemática. Bien sabemos que en el área de la expresión artística se ofrecen tantas respuestas como educandos participen de la actividad. Al descuidar u omitir actividades de arte en algunas de nuestras escuelas, se le impide a la población estudiantil el desarrollo de su cerebro en toda su magnitud, situación que no se debe permitir, pues lo que conviene es el ofrecimiento de acciones que fortalezcan el crecimiento de una personalidad integral, no parcial.

Finalizo este apartado indicando que el trabajo realizado fortaleció, en la población participante, el desarrollo de un potencial intelectual que afectó de manera positiva su sensibilidad. Revalorar las actividades de expresión artística en esa escuela fue sinónimo de "revalorizar" la capacidad para pensar y para hacer trabajos personales y únicos.

Patricia Stokoe y Alicia Sirkin citada por Iris Pérez (2002, p. 23), indican:

...no se enseña a crear (porque "crear" es una capacidad constitutiva); no se enseña "cómo" crear (porque las conexiones son siempre singulares e intransferibles); pero sí 
es posible estimular el proceso que conduce a la creación. Para ello es necesaria una acción dirigida simultáneamente a:

1) desarmar los bloqueos perturbadores;

2) alimentar experiencias de entrenamiento sensorial, imaginativo, lúdico, etc.;

3) enseñar "lenguajes" con los que el sujeto pueda desplegar su capacidad de idear y construir realidades nuevas (desde los lenguajes sensibles hasta el lenguaje verbal que organiza y da significado a todos los demás).

Como en cualquier proceso de la vida, cada quien participó de acuerdo con sus experiencias, intereses y su forma de ser.

La experiencia hizo posible un verdadero desarrollo de las potencialidades de quienes se involucraron, así como el derecho a la participación de todos y todas en igualdad de condiciones, sin distingo de edad, contextos sociales y formación académica.
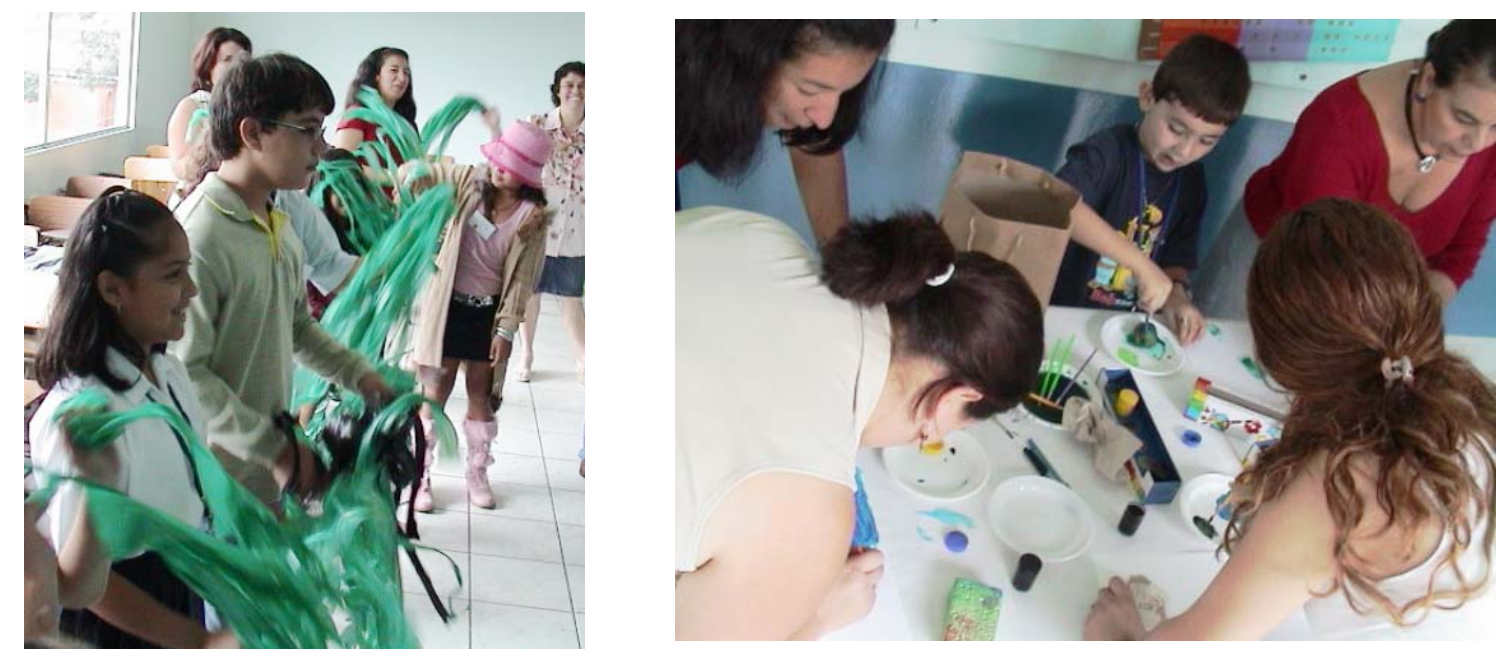

\section{El enfoque globalizador en la enseñanza}

Como docentes debemos tener presente que las demandas de los tiempos actuales evidencian la necesidad de una educación que responda a los intereses de una sociedad en constante cambio; por lo que el sistema educativo debe responder de manera sistemática al mejoramiento de la calidad de vida de sus ciudadanos.

Por consiguiente, quienes asumen la responsabilidad de organizar planteamientos curriculares en el Ministerio de Educación Pública, requieren tener una visión clara y global 
en cuanto a considerar que el sistema educativo es dinámico y se va transformando con el transcurso del tiempo, aumentando y diversificando sus necesidades de educación, así como variando su distribución en el territorio. Esto quiere decir que se expande por causa de nuevos componentes u ofertas que se le agregan. Por lo tanto, el sistema educativo crece en cuanto al factor cuantitativo y en el sentido cualitativo, ya que está obligado a evolucionar en cuanto a la modernización de sus estructuras, actualización de los contenidos programáticos y las técnicas de enseñanza, por lo que requiere de ofertas concretas de instituciones públicas como las Universidades que coadyuvan en esa transformación, pues la educación de calidad constituye para un pueblo la mejor garantía del disfrute de sus derechos, (Dengo, 2004).

Con el propósito de que la enseñanza responda a los intereses de la ciudadanía, quien organiza los procesos de enseñanza y aprendizaje debe tener claridad respecto a cómo se pueden interrelacionar los diferentes componentes que conforman el contexto de aula, sin perder de vista los fines de la educación y, en consecuencia los planteamientos curriculares que permiten el desarrollo integral de la población estudiantil.

El personal docente debe comprender que una de las actividades más representativas de su acción en el ámbito educativo es la enseñanza, considerada ésta como una toma de decisiones compleja y como el modo peculiar, único e irrepetible de orientar el aprendizaje, por lo que es necesaria la creación de escenarios que inviten a la imaginación, a la creación, a la reflexión, entre éste y el estudiantado. Lo anterior conlleva a una práctica pedagógica reflexiva e indagadora, en la que se adapta el currículum escolar al contexto de aula y al saber académico de los estudiantes, con el propósito de que éstos construyan aprendizajes significativos en función de sus propios valores.

Con el propósito de planificar y organizar de la mejor manera su trabajo diario y al considerar que no existe un único método que resulte efectivo y válido para todas las situaciones de enseñanza y aprendizaje, le corresponde al docente interpretar de manera reflexiva y flexible los contenidos emanados por el Ministerio de Educación Pública. Por lo tanto, le conviene asumir responsabilidades como las que a continuación se mencionan:

- Poseer una actitud investigativa y deseos de innovar su práctica pedagógica mediante el estudio e indagación de teorías, modelos o fundamentos que le faciliten una mayor comprensión y valoración de las decisiones más adecuadas para comprender que cada estudiante posee su propia capacidad intelectual, así como sus intereses y deseos personales. 
- Partir de una visión de aprendizajes activos, en atención a la complejidad e incertidumbre, así como reconsiderar la fuerza del conocimiento y la formación de sus estudiantes a partir de los problemas más representativos de su realidad personal y social.

- Respecto de la experiencia que se menciona, al planificar el trabajo de aula se deben tener presente tanto los aspectos relativos a los desarrollos; cognitivo, socioafectivo y psicomotor, como los que corresponden al área de la expresión artística (intelectual, social, estético, afectivo, físico, emocional, incluyendo la comunicación oral de cada uno de sus estudiantes), pues éstos se reflejan en las expresiones creativas que elabora la población participante, sean éstas personales o colectivas.

Para que el personal docente pueda llevar a la práctica los aspectos mencionados, debe comprender que la "verdadera enseñanza" es la que asegura el aprendizaje, pero no el aprendizaje fijo, de datos o de informaciones puntuales (lo que se denominaba mera instrucción), sino la que provoca cambios para reorientarse y trazar nuevos caminos, para diseñar procedimientos, para solucionar problemas y para alcanzar nuevos conocimientos que corresponden a logros de su propia reflexión.

Sarramona J. (2000), considera que la acción pedagógica tiene diversas formas de llevarse a cabo, justificadas por el hecho de que hay variadas formas de aprendizaje. Lo lógico sería que cada tipo de aprendizaje corresponda a una determinada forma de materializarlo, por lo que conviene hacer las siguientes consideraciones:

a. Los diversos tipos de aprendizaje se corresponden con las posibilidades evolutivas del sujeto educando.

b. De acuerdo con esta evolución, persisten diferentes tipos de aprendizaje que se logran de acuerdo con los objetivos que se pretenden alcanzar, por lo que conviene una adecuada organización y aplicación de técnicas didácticas que permitan la construcción de aprendizajes simples y complejos, ya que con preponderancia permanecen estos últimos una vez alcanzada la madurez evolutiva.

De las reflexiones mencionadas, se interpreta que la teoría pedagógica o los modelos que rigen una determinada manera de concebir la educación se fundamentan en las correspondientes teorías del aprendizaje, ya que educar es, ante todo, lograr que el educando aprenda, advirtiendo que aprender supone adquirir no solo conocimientos, sino que también habilidades y actitudes. 
El mismo autor expresa que los modelos de acción educativa se pueden considerar también "modelos didácticos", cuando se vinculan con los procesos de enseñanza y aprendizaje. Por lo tanto, constituye una tarea de gran responsabilidad para el docente el conocimiento y las respectivas posibilidades de cada modelo pedagógico, así como su elección y aplicación, labor que debe realizar de manera consciente y reflexiva.

De acuerdo con Flores O. R. (1999,32), un modelo pedagógico es la representación de las relaciones que predominan en el acto de enseñar, es también un paradigma que puede coexistir con otros, y sirve para organizar la búsqueda de nuevos conocimientos en el campo de la pedagogía.

Toda teoría pedagógica, según Flores, trata de responder de manera sistemática y coherente al menos a las siguientes preguntas:

¿Qué tipo de ser humano se quiere formar?

¿Con qué experiencias crece y se desarrolla un ser humano?

¿Quién debe impulsar el proceso educativo?

¿Con qué métodos y técnicas puede alcanzarse mayor eficacia?

Estas interrogantes podrían ser respondidas por diferentes especialistas; sin embargo, en ambientes de escolaridad le corresponde al docente abordarlas de forma transdisciplinaria, por lo que le conviene poseer una formación académica idónea, tanto en el campo de su especialidad, como en el área pedagógica, que le permita responder de la manera más adecuada las preguntas indicadas, así como otras que considere pertinentes.

Es importante tener presente que cada modelo pedagógico tiene sus ventajas, ya que ninguno es perfecto ni aplicable por completo, por lo que le compete al docente, previo a la organización de su labor, investigar, estudiar y seleccionar el que mejor le convenga, de acuerdo con el nivel académico y edad de sus estudiantes, el tema o materia por estudiar, sin obviar el contexto social y personal. Éste no necesita plegarse a ningún modelo; sin embargo, toda enseñanza de calidad requiere de profesionales que tengan claridad respecto a lo que van a enseñar, que sientan gusto por lo que hacen, sin menospreciar los conocimientos previos y el contexto de sus estudiantes.

Conviene recordar que mientras la enseñanza es una actitud intersubjetiva, que se produce mediante la interacción entre varios sujetos -al menos dos- sobre algún tema determinado o material previamente seleccionado por el docente que desea suscitar una conversación, acción o reflexión de la que se espera algún aprendizaje; el verdadero aprendizaje ocurre en el interior de cada persona que aprende, es subjetivo, y su dominio se 
puede exteriorizar mediante diversas acciones específicas, palabras, redacción de textos, gestos, efectos musicales, grafismos, expresión corporal, entre otros.

Arnobio Maya (2000, p. 53), indica que el docente como gestor y facilitador de los procesos didácticos, requiere fundamentar su labor, pues le permite tener claridad respecto a su gestión, ya que:

...la práctica docente como el eje operativo de los procesos de enseñanza y aprendizaje o del proceso docente educativo, no se refiere exclusivamente a la aplicación de técnicas, tareas o actividades que se llevan a la práctica de una manera empírica o aislada, por repetición de experiencias intuitivas, sin el debido sustento comprensivo y explicativo de una teoría o conceptualización, validada científicamente, por ello, es necesario comprender que ninguna práctica debe darse sin una teoría que la acompañe o sin una base sobre la cual se construye, toda práctica docente debe poseer un planteamiento teórico que la sustente.

Como parte de la experiencia académica en la Escuela de Platanares, las docentes o facilitadoras del aprendizaje inician un proceso de investigación y reflexión respecto del enfoque teórico que fundamentaría la planificación de las experiencias artístico-pedagógicas. De esta manera, se acude al enfoque globalizador de la educación, por presentar una interesante estructura para organizar los procesos de enseñanza y aprendizaje denominada "integración de temas". Además, las actividades se planifican a través de la "modalidad de talleres o proyectos de trabajo".

Según Panero N., Colombo S., Paronzini P. y Alfonso M. $(2001,15)$, la modalidad de taller o proyectos de trabajo es la mejor manera de construir aprendizajes significativos, ya que promueve:

- la creatividad

- el respeto mutuo

- el descubrir las diferencias operando sobre limitaciones y potencialidades

- un ámbito donde lo lúdico constituye uno de los recursos más propicios para el desencadenamiento de acciones

- la confrontación de diversos puntos de vista

- la aceptación de los resultados de los trabajos de experiencias creativas como alternativa para construir el aprendizaje, así como la aceptación a la diversidad 
Tomando en consideración los argumentos expuestos, las maestras interpretan los lineamientos curriculares que corresponden a la poesía y a las artes plásticas, mediante la planificación de proyectos de trabajo mediante los cuales se llevan a la práctica novedosas técnicas metodológicas y artísticas que se ajustan a los intereses, habilidades y aptitudes de la población infantil y adulta.

Como se expresara anteriormente, en el enfoque globalizador los participantes logran los objetivos desde un planteamiento integrado de los conceptos o contenidos, los procedimientos o las situaciones de aprendizaje y los valores o actitudes, lo que facilitó el ofrecimiento de respuestas globales a los aprendizajes adquiridos. En otras palabras, los temas que sirven de enlace entre los conceptos, los procedimientos o situaciones de aprendizaje y las actitudes, se visualizan mediante la planificación de variadas técnicas metodológicas y artísticas, las cuales se concretan a través de los talleres de arte o proyectos de trabajo. Es importante mencionar que para la programación de las actividades en la institución siempre se consideraron los conocimientos previos, los hábitos de lectura, las experiencias de arte, las edades y los intereses de la población participante, situación que favoreció el logro de aprendizajes efectivos.

\section{La actividad creadora en la escuela, su importancia}

Como se indicara en el apartado anterior, luego de un proceso de investigación respecto a las teorías que fundamentarían la organización de las actividades artístico-pedagógicas, se realizó un diagnóstico mediante el cual se identificaron los conocimientos que poseían los participantes en ambas áreas (poesía y artes plásticas), así como sus habilidades, destrezas, intereses e inquietudes; lo que sirve de insumo para la planificación de actividades a través de la modalidad de talleres.

Algunas de las premisas que favorecieron el desempeño de los participantes se indican a continuación:

a. Quienes participan en este tipo de actividades son capaces de expresar plásticamente lo que les gusta y lo que les disgusta, sus emociones internas, es decir, sus sentimientos, sus conocimientos, sus vivencias y sus experiencias.

b. Algunas veces no pueden mostrar las emociones abiertamente, por ejemplo con palabras o mediante la expresión musical o escrita, pero lo hacen con una gran facilidad mediante el dibujo o la pintura, por lo que las artes plásticas se pueden transformar en un valioso recurso que permite canalizar emociones. Además, le permiten al adulto conocer 
mejor a sus hijos e hijas, y de esta manera detectar algún tipo de problema en su aprendizaje.

c. La organización de actividades creadoras en el aula hace que las personas se vuelvan más sensibles y conocedoras de sí mismas.

d. La actividad artística practicada desde la infancia forma personas más adaptadas a la sociedad, lo que les permite desarrollar su autoestima y su seguridad, pues produce una gran emoción saber que uno es capaz de producir cosas que antes no existían, en este tipo de experiencias el arte actúa como mediador entre la inteligencia y las emociones, entre el cerebro y el corazón.

A través de la expresión artística, indica Pérez I. (2002), los estudiantes también aprender a respetarse y a respetar a los otros, a desarrollar su autoestima, a respetar las reglas, a ser responsables, a tomar decisiones con libertad, a valorar su trabajo y el de los otros, a trabajar en equipo y a desarrollar conocimientos, habilidades, destrezas y aptitudes manuales y técnicas.

Como se indicara al inicio del artículo, la experiencia académica permitió la integración de las áreas de expresión artística: artes plásticas y poesía, lo que favoreció los desarrollos cognitivo, socio-afectivo y psicomotor. Luego de un intenso estudio investigativo, las docentes tienen claridad respecto al modelo teórico que fundamentaría su trabajo de aula, ya que al acudir a la modalidad de talleres o proyectos de trabajo se benefició la planificación de actividades de aprendizaje integradas, de tal manera que la población estudiantil y sus familiares interpretaron, transmitieron y concretaron los mensajes emitidos por los poemas y cuentos mediante experiencias plásticas, comprendiendo que se trata de un proceso lúdico, en el que se permite, no solo la expresión de la persona, sino el disfrute de lo que hace, sabiendo que las creatividades son aceptadas sin que medien valoraciones subjetivas.

Según Bornemann Elsa (1977, p. 14), la

poesía infantil es toda aquella poesía creada por un escritor adulto e intencionalmente destinada al público infantil, y también aquella que -sin que su autor se lo haya propuesto- puede ser dirigida a los niños y gozada por éstos, como sucede con cantidad de poemas que es posible espigar de la labor poética de ciertos autores. No se incluye dentro de esta definición la poesía creada por los niños -ya sea ésta producto natural de una incipiente vocación literaria o resultado de algún ejercicio escolar- de indudable interés para maestros, pedagogos, lingüistas y psicólogos, pero 
generalmente ajena a lo que un poema debe comprender para ser considerado obra artística.

Sabiendo que los libros de poemas enriquecen la sensibilidad, el lenguaje, la comprensión y las experiencias de la población infantil, las docentes (con la asesoría de las educadoras de la Sociedad Internacional de Educadoras Delta, Kappa, Gamma) se dieron a la tarea de adquirir textos cargados de imágenes y contenidos que motivaron y se constituyeron en generadores de movimientos internos, es decir, en movilizadores de las más puras potencialidades del espíritu infantil, (Bornemann E. 1977). Las actividades hicieron posible que tanto las maestras, como los niños, las niñas y sus familiares, disfrutaran escuchando y reflexionando sobre el contenido de los textos y las imágenes que ilustraban las poesías y los cuentos.

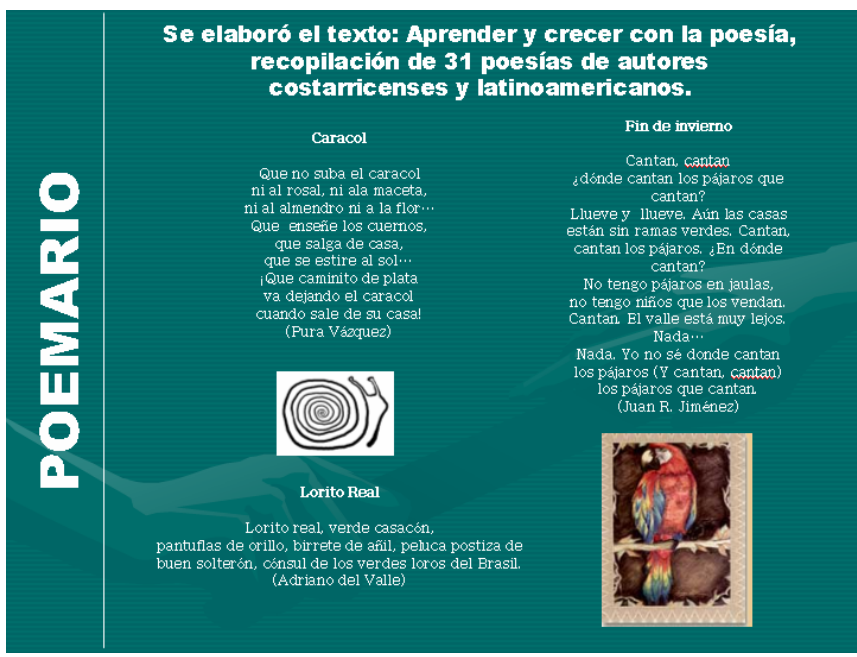

Como parte de la planificación de las actividades, los participantes realizaron experiencias pictóricas con diversos materiales sobre espacios planos y bidimensionales que permitieron la realización de trabajos cargados de creatividad y emotividad, situación que provocó diversos estados de ánimo: sorpresa, alegría, asombro, aprobación, y también rechazo.

Conviene recordar que cuando los participantes intervienen de manera natural y espontánea en sus propios procesos creativos, en este tipo de experiencias transmiten su personalidad, su grado de adquisición de conocimientos, su capacidad de percibir y comunicar emociones y sentimientos, sus habilidades y destrezas que contribuyen al fortalecimiento de su desarrollo personal y social.

Deseo concluir este apartado indicando que la literatura indagada le permitió a las maestras comprender que el proceso de creación se produce al estimularlo, por lo que fue necesaria una acción dirigida a alimentar experiencias sensoriales, imaginativas, lúdicas, así como la experimentación con lenguajes que les permitiera su capacidad de idear y de construir realidades nuevas, motivo por el cual se acudió a los lenguajes verbal y gráfico- 
plástico. Cabe destacar que los sentidos se estimularon de diversas maneras, a continuación se hace referencia a algunas de las actividades incentivadoras que se vivenciaron:

- Se solicitó a la población mirar la naturaleza y los elementos que la conforman, sus árboles, sus ramas, los troncos, las texturas, los colores, la puesta de sol, así como escuchar los sonidos que emite la naturaleza. Posteriormente imitaron con su cuerpo (piernas, hombros, brazos, cabeza y dedos), los elementos que observaron. Luego se les invitó a que pintaran y dibujaran con diversos materiales (pinturas, lápices, arena, marcadores, papeles y goma) y técnicas artísticas (acuarelas, impresiones, dibujos y pinturas) las experiencias vividas.

- Al considerar que la expresión plástica es un lenguaje que permite representar la realidad, la fantasía, lo mismo que ideas y sentimientos, se organizaron espacios que estimularon la imaginación y el disfrute de lo que se hacía. La idea era que las personas se nutrieran de imágenes percibidas mediante el contacto natural y posteriormente fueran capaces de crear paisajes, personajes y otros elementos imaginarios; también se inventaron cosas nunca vistas y paisajes fantaseados. La experiencia permitió el descubrimiento de nuevas formas de ver las cosas, de expresarlas y de representarlas, manteniendo siempre el respeto por lo que las otras personas realizaron.

- Se comenta la importancia de la literatura como un recurso creativo que favorece el desarrollo de la personalidad del niño, del joven y del adulto, por lo que se escuchan cuentos y canciones que favorecen el trabajo interactivo, y con ayuda de diversos recursos pictóricos, la población adulta informa de manera libre y espontánea el tipo de actividades que organizaría en su hogar con la colaboración de los otros miembros de su seno familiar: esposo, abuelos, abuelas, y otros.

- Se leyeron y narraron cuentos y poesías, posteriormente el contenido fue interpretado utilizando la expresión corporal y la creación de ritmos con la ayuda de elementos del medio: conchas, arena, hojas, y con la emisión de sonidos producidos con el cuerpo como silbidos, suspiros, palmadas y el roce de las uñas, entre otros.

- Se crearon ambientes que influyeron en la narración y reconstrucción de cuentos mediante la expresión oral. Luego se escribieron y se pintaron sueños. 
- En espacios abiertos como jardines, corredores y la plaza de deportes de la institución, se organizaron experiencias que estimularon la imaginación, la creación de poesías en las que los personajes principales eran los mismos estudiantes y familiares.

Las actividades mencionadas, así como otras sugeridas por los mismos participantes sirvieron de incentivo al iniciar cada uno de los talleres, lo que facilitó un trabajo cargado de entusiasmo y alegría.

\section{Los talleres o proyectos de trabajo, un recurso metodológico que permitió la integración de la poesía y las artes plásticas}

Con el propósito de dinamizar y hacer más activa y amena la enseñanza, y por considerar que las experiencias creativas son una inagotable fuente de ideas, se acudió a la organización de "talleres o proyectos de trabajo" mediante los cuales se planificaron actividades desde un planteamiento de integración curricular que responde al modelo educativo globalizador.

Cada proyecto se organiza alrededor de temas integradores, en el que los objetivos, contenidos, procedimientos, materiales, las técnicas de expresión plásticas, los intereses, experiencias, conocimientos previos, así como las edades de la población participante, fueron elementos fundamentales para la planificación de un trabajo de calidad. La experiencia favoreció en cada uno de los participantes su "autoidentificación", de manera que pudiera decir con orgullo y satisfacción "esto es mío", situación que permitió plantearse nuevos propósitos y retos, así como seleccionar los materiales, técnicas y procedimientos más adecuados para la concreción de sus propias formas de expresión.

Con el propósito de que la creatividad surgiera sin obstáculo, las gestoras de los procesos de enseñanza se dieron a la tarea de crear agradables ambientes dentro y fuera del aula. Es importante mencionar que la población adulta se contagió del entusiasmo de los niños y las niñas, y sin temor a la crítica, se dio cabida a la exploración, a la experimentación,

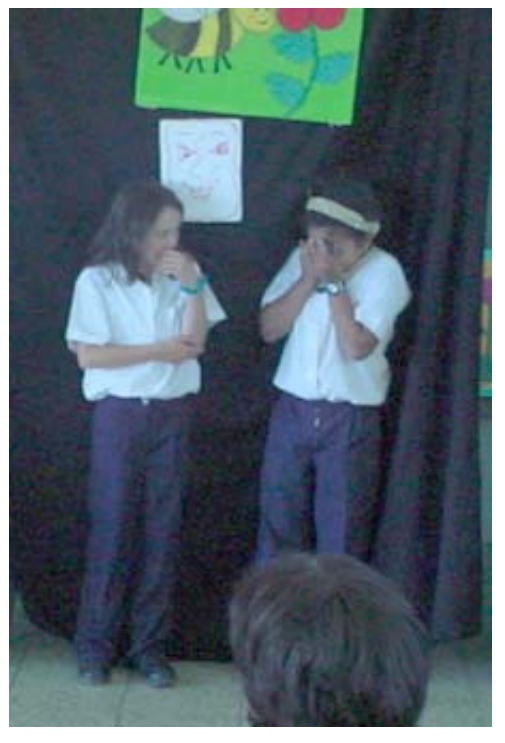
al juego y al entusiasmo, elementos indispensables para la creación personal y colectiva. 
De acuerdo con Pérez I. (2000), todo acto creador suele empezar como un juego en el que las experiencias invitan a la imaginación y la fantasía. Toda creación primero es imaginada en la mente de su creador. El juego es un proceso vital en el desarrollo humano ya que favorece la creatividad y la salud mental. En el apartado anterior se describen las actividades que las maestras organizaron y estimularon el trabajo de aula, el cual fue disfrutado plenamente por estudiantes y familiares.

Panero N., Colombo S., Paronzini P. y Alfonso M. (2001, pp. 18-19) mencionan algunos aspectos que favorecen el desarrollo de la actividad:

- En relación con el equipo docente:

- Buenas relaciones vinculares.

- Conocimiento claro de las disciplinas

- Trabajo cooperativo.

- Actualización a través del perfeccionamiento docente.

- Criterios e instrumentos de valoración que permitan hacer modificaciones durante el desarrollo de las actividades.

- En relación con la población participante:

- Planificar la evaluación inicial de los conocimientos previos.

- Promover su participación permitiéndoles proponer y decidir en determinados aspectos del proceso.

- Desarrollar hábitos y actitudes de conveniencia grupal.

- Favorecer su autoevaluación.

- Facilitar la exposición de sus producciones.

- En relación con el espacio-aula y los recursos materiales:

- Espacio amplio y bien organizado.

- Variedad de materiales.

- En relación con la institución:

- Equipo directivo abierto al cambio.

- Proyecto institucional democrático.

- Flexibilidad horaria. 
Las reflexiones mencionadas se convirtieron en los ingredientes esenciales para la planificación de las actividades metodológicas, ya que facilitaron la concreción de contenidos curriculares de manera más agradable y placentera.

Sin embargo, para que las actividades se llevaran a la práctica con todo éxito, la población participante (docentes, estudiantes y familiares), debió asumir con pasión e interés las siguientes responsabilidades:

\section{- Las docentes:}

- Asumieron el reto de planificar innovadoras situaciones de aprendizaje o actividades a poblaciones diversas, en las que la edad, los conocimientos previos, las actitudes y los intereses se mezclan para participar en actividades lúdicas, que les permitiera libre interpretación de poesías y los cuentos mediante experiencias plásticas.

- Como se indicara en apartados anteriores, participaron en procesos de investigación y reflexión respecto al enfoque teórico que fundamentaría la organización de las experiencias artístico-pedagógicas, por lo que acudieron al enfoque globalizador de la educación ya que permite una interesante forma de organizar los procesos de enseñanza y aprendizaje mediante la modalidad de talleres o proyectos de trabajo que facilitaron la integración de los contenidos mediante temas integradores.

- Planificaron cada uno de los talleres o proyectos de trabajo de acuerdo con la estructura curricular mencionada, por lo que se aplicaron los procedimientos metodológicos más adecuados para trabajar la integración de la poesía y las artes plásticas; por este motivo se ofrecieron interesantes y llamativas poesías y cuentos. En todo momento se tiene presente la ambientación agradable del aula, los elementos incentivadores que despiertan el interés hacia el trabajo, así como el cuidado de presentar los materiales y técnicas de arte de manera atractiva.

\section{- La población infantil y adulta:}

- Se caracterizó por una participación y colaboración sistemática durante las actividades académicas programadas.

- Mediante actividades de sensibilización descubrieron su potencial creativo, lo desarrollaron y lo concretaron mediante experiencias lúdicas que se realizaron como parte de los procesos. 
- Conocieron y llevaron a la práctica normas de disciplina, tolerancia, respeto, orden, limpieza, así como otros principios indispensables para mantener una buena convivencia.

- Participa en la exhibición de sus trabajos y respeta los realizados por las otras personas.

\section{Población participante en la actividad}

Como se indica en la introducción del artículo, en la actividad participaron las siguientes poblaciones:

- dos maestras que poseen su Bachillerato en Educación Primaria y una experiencia profesional que permitió un trabajo novedoso y de calidad.

- veintiocho estudiantes que corresponden a las secciones: A y B del Tercer Grado, de la Educación General Básica, entre los 9, 10 y 11 años de edad.

- veintisiete padres y madres de familia de esos estudiantes.

- un grupo de docentes que pertenecen la Sociedad Internacional de educadoras Delta, Kappa, Gamma, quienes con su experiencia, dedicación y formación académica brindan asesoría directa a las maestras en las siguientes áreas: investigación, evaluación de los aprendizajes, literatura infantil, cómo contar cuentos, artes plásticas, música. Aunque la asesoría se planificó a través de un trabajo interactivo con las docentes, en algunos talleres se trabajó con estudiantes y familiares.

Al considerar que los familiares participarían de las mismas actividades que sus hijos e hijas, surgió una relación mucho más estrecha y permanente entre ellos mismos, la cual fortaleció la comunicación y las relaciones interpersonales, situación que favoreció a la escuela como institución formadora al aproximarse a la vida real y de esta manera los padres se aproximaron a la vida escolar, ya que en la formación de nuestros hijos e hijas, tanto la familia como los profesionales deben buscar de manera conjunta los mismos objetivos y de esta manera debe surgir la distribución de responsabilidades.

Considerando que la institución por medio de sus docentes está obligada a interactuar con el medio familiar, la actividad desde su origen toma en cuenta la participación de la familia. Sabemos que la escuela no puede continuar creyendo que sólo ella tenga el poder educador. Hay que devolver a la familia su capacidad formadora y transformadora de 
cambios. La actividad trató de reforzar la propia imagen como padres y madres, valorándola como valiosa e insustituible. Conviene recordar que el docente no puede ser el sustituto de las familias ni las familias pueden sustituir el docente: se trata de una labor interactiva, de conjunto, de colaboración, de cooperación y de mutuo respeto. (Soto Ronald e Hinojo Francisco. 2005, p. 194).

\section{Conclusiones respecto a la actividad realizada}

A continuación se hace referencia a algunos de los cambios cualitativos que se atribuyen al trabajo desarrollado:

- El proyecto transformó las prácticas de lectura de poesía y cuentos obsoletas y tradicionales en prácticas de lectura interactivas e innovadoras, de manera que los participantes tuvieron la oportunidad de disfrutar, reflexionar y aprender mediante su participación en las diversas dinámicas que se organizaron.

La participación sistemática y entusiasta de las maestras, estudiantes, padres y madres de familia, fue fundamental para la promoción, adquisición y fortalecimiento de hábitos de lectura.

- Es importante mencionar que la adquisición de conocimientos, habilidades y destrezas mediante la participación sistemática en los diversos talleres, no solo mejoraron la comprensión de los textos, sino la construcción de aprendizajes en diversas áreas del saber; música, artes plásticas, expresión corporal, elaboración de poesías y cuentos.

- Como parte de la actividad de clausura, los participantes lograron llevar a la práctica los conocimientos adquiridos en los diversos talleres mediante una actividad lúdica, en la que integraron las diversas áreas expresivas desde un planteamiento unificado.

- Según manifestaron los padres y madres de familia (la mayoría sin formación profesional), ..." hemos tomado conciencia de la importancia de participar en actividades que invitan a la convivencia, a la motivación y a la adquisición de hábitos que se consideran fundamentales para nuestro desarrollo cognitivo y afectivo. Esperamos que estos talleres se repitan". 
- La organización de las actividades por parte de las maestras, no solo reflejaron un gran compromiso con la educación estudiantil, sino con una población adulta que generalmente se acerca a la escuela a escuchar quejas y comentarios negativos de sus hijos e hijas, a recibir sus calificaciones trimestrales, y pocas veces es tomada en cuenta para actividades que fomentan su crecimiento personal.

- La planificación de las actividades a cargo del grupo de asesoras incluyó la recopilación de poesías y cuentos de autores de la literatura hispanoamericana mediante la elaboración de un texto denominado "La enseñanza de la literatura en primero y segundo ciclo", el cual presenta diversas técnicas innovadoras para la enseñanza de la poesía y la narración de cuentos.

- Como parte de los objetivos del curso, los participantes organizaron una actividad culminatoria o clausura del proyecto, en el que llevaron a la práctica los aprendizajes adquiridos. A continuación se mencionan algunas de éstas:

- una exposición de libros elaborados con papeles, cartones y telas.

- confección de un árbol navideño con

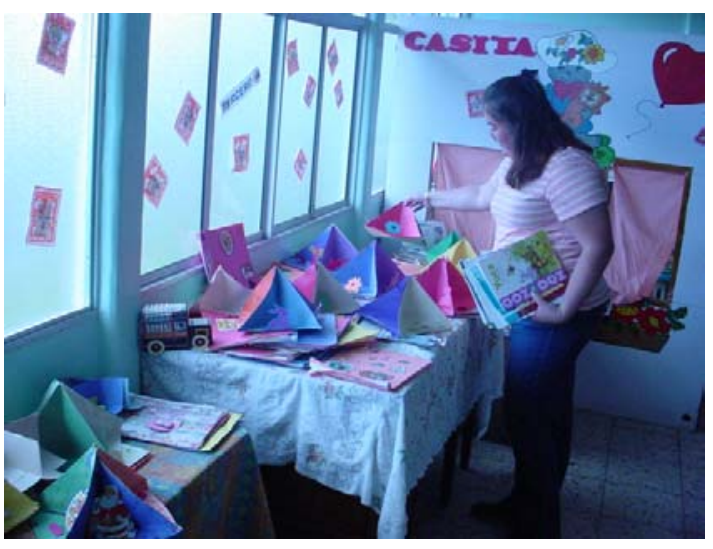
cartones, el cual se decoró con pequeños libros elaborados por ellos mismos e ilustrados con poesías y dibujos.

- exposición de carátulas para el texto "La enseñanza de la literatura en primero y segundo ciclo".

- exhibición de una obra de teatro en la que participaron familiares $y$ estudiantes.

- presentación de una poesía coral en la que evidenció la expresión corporal y musical.

La actividad de clausura se aprovechó para entregar certificados de participación, aprovechamiento o de asistencia, tanto a estudiantes como a sus familiares $y$

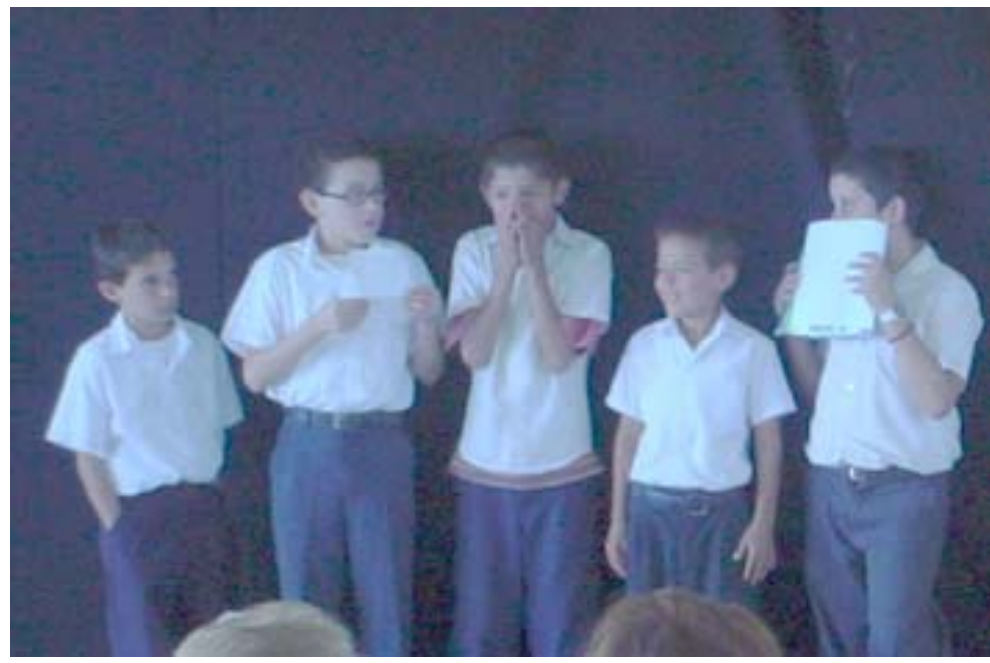

Volumen 6, Número 1, Año 2006, ISSN 1409-4703 
maestras. Se instaló una Biblioteca en la Institución y se obsequiaron 150 libros de cuentos y poesías de parte de las educadoras que tuvieron a su cargo el respectivo asesoramiento.

\section{Comentarios personales}

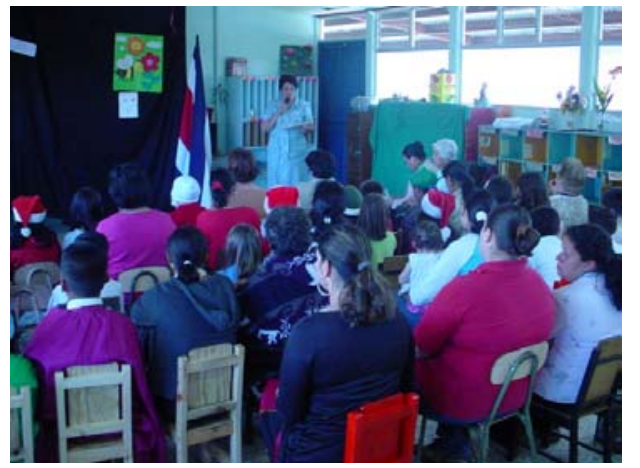

- En la actividad realizada en la Escuela de Platanares, se evidenciaron cambios significativos en cuanto a la adquisición de hábitos de lectura, ya que tanto los papás como las mamás participantes, asumieron tareas y responsabilidades que implicaron cambios en sus rutinas. Debieron organizar actividades interactivas en el seno familiar que les permitiera la interpretación de contenidos, la participación en juegos y la realización de experiencias de taller.

- El concepto metodológico que se aplicó para enseñar la poesía, requirió especialmente de las artes plásticas para su concreción, aunque también se trabajó con otras áreas expresivas como la música y la expresión corporal.

- Es importante mencionar que la actividad de clausura culminó con una producción bastante creativa de quienes habían participado durante todo el año, lo que permitió apreciar su alto grado de compromiso, dedicación y empeño.

- Se espera que las maestras participantes conviertan sus aprendizajes en actividades autogestionarias y cogestionarias, y las puedan llevar a la práctica en contextos educativos que presenten desigualdades de tipo social, económico, intelectual, pues se estaría contribuyendo al logro de una sociedad más justa y equitativa.

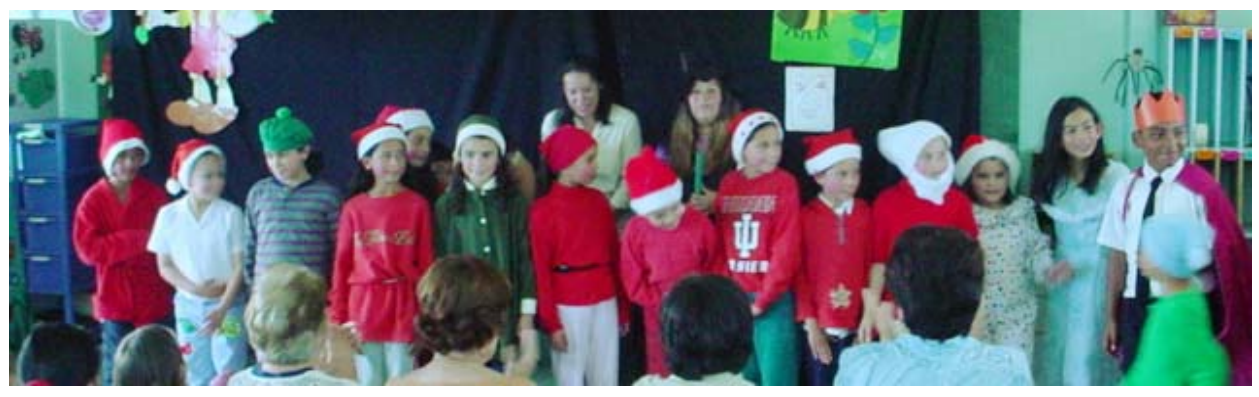


- Finalmente, deseo enfatizar el hecho de que se tomara en cuenta la participación un grupo de padres y madres de familia en actividades de índole académico, ya que su crecimiento como personas contribuirá de alguna manera en el desarrollo académica de sus hijos e hijas.

Actividades de este tipo favorecen el logro de aprendizajes que contribuyen a la formación de ciudadanos con alto grado de conocimiento, y por lo tanto capaces de tomar decisiones que contribuyen a su propio beneficio.

Deseo concluir con una cita de A. Alvarado y G. Murano. (1990), que menciona algunas actitudes que el maestro debe tener presente al organizar su trabajo de aula:

- Debe trabajar amorosamente con sus estudiantes.

- Ser apasionado de las actividades expresivas.

- Fomentar en el alumno el pensamiento divergente, ayudándolo a buscar respuestas para la satisfacción de él mismo.

- Respetar por igual todas las ideas procedentes de los estudiantes.

- Disfrutar con los alumnos de sus descubrimientos.

- Favorecer el proceso más que el resultado, ayudándole a autoevaluarse.

- Sensibilizar al alumno frente a la naturaleza y frente a su condición humana.

- Atender la problemática de cada estudiante en particular, pero sin perder de vista al grupo.

- Promover temas de interés.

- Ser flexible con los materiales y técnicas. La población estudiantil debe conocer variedad para que pueda representar lo que desee.

- No olvidar que, para fomentar cambios de actitud en los alumnos, debemos empezar por cambiar nosotros. 


\section{Referencias}

Alfonso Mónica de, Panero Norma de, Colombo Susana de, Paronzini Palmira de. (2001). Educación Artística y C.B.C. Talleres de Plástica, Música, Teatro y Expresión Corporal. Nivel Inicial y E.G.B. Ciudad: Artes Gráficas Villarruel-Rosario-Santa Fe.

Alvarado, Ana y Murano, Gabriela. (1990). El taller de plástica en la escuela. Teoría y práctica. Argentina: Editorial Troquel.

Bornemann, Elsa. (1977). Poesía infantil, estudio y antología. Buenos Aires: Editorial Latina.

Castro Bonilla, Julieta. (2005). Lineamientos metodológicos para incorporar la Expresión plástica en el planeamiento escolar. Educación: Revista de la Universidad de Costa Rica. 28(2): 221-232.

Flores O., Rafael. (1999). Evaluación Pedagógica y Cognición. Bogotá, D.C., Colombia: Mc Graw Hill Interamericana.

Maya, B. Arnobio y otros. (2000). La Práctica Pedagógica Innovadora en el Aula y en la Escuela y su Sistematización. San José, C.R.: UNESCO, Ministerio de Educación Pública-SIMED.

Pérez Ulloa, Iris. (2000). Didáctica de la Educación Plástica, el taller de arte en la escuela. Buenos Aires Argentina: Editorial Magisterio del Río de la Plata.

Sarramona, Jaume. (2000). Teoría de la Educación. Reflexión y normativa pedagógica. Barcelona: Editorial Ariel, S.A.

Soto Calderón, Ronald e Hinojo Lucena, Francisco Javier. (2004). La colaboración entre maestros/maestras y padres/madres para atender a la diversidad en las instituciones educativas. Educación: Revista de la Universidad de Costa Rica. 27(1): 185-201. 